\title{
Papers
}

\section{Use of evidence based leaflets to promote informed choice in maternity care: randomised controlled trial in everyday practice}

\author{
A O'Cathain, S J Walters, J P Nicholl, K J Thomas, M Kirkham
}

\begin{abstract}
Objective To assess the effect of leaflets on promoting informed choice in women using maternity services.

Design Cluster trial, with maternity units randomised to use leaflets (intervention units) or offer usual care (control units). Data collected through postal questionnaires.

Setting 13 maternity units in Wales.

Participants Four separate samples of women using maternity services. Antenatal samples: women reaching 28 weeks' gestation before $(n=1386)$ and after $(\mathrm{n}=1778)$ the intervention. Postnatal samples: women at eight weeks after delivery before $(n=1741)$ and after $(n=1547)$ the intervention.

Intervention Provision of 10 pairs of Informed Choice leaflets for service users and midwives and a training session for staff in their use.

Main outcome measures Change in the proportion of women who reported exercising informed choice. Secondary outcomes: changes in women's knowledge; satisfaction with information, choice, and discussion; and possible consequences of informed choice.

Results There was no change in the proportion of women who reported that they exercised informed choice in the intervention units compared with the control units for either antenatal or postnatal women. There was a small increase in satisfaction with information in the antenatal samples in the intervention units compared with the control units (odds ratio 1.40, 95\% confidence interval 1.05 to 1.88 ). Only three quarters of women in the intervention units reported being given at least one of the leaflets, indicating problems with the implementation of the intervention.

Conclusion In everyday practice, evidence based leaflets were not effective in promoting informed choice in women using maternity services.
\end{abstract}

\section{Introduction}

There is a growing consensus that people should be informed about, and able to influence, decisions about their own health care. ${ }^{2}$ Decision aids, which present the options available to patients with evidence from research on their effects, can help people to participate in decisions about their care. ${ }^{3}$ Midwives Information and Resource Service (MIDIRS) and the NHS Centre for Reviews and Dissemination have produced a set of 10 leaflets on informed choice in maternity care. The leaflets summarise evidence on 10 decisions that women face in pregnancy and childbirth to encourage their involvement in decisions about their own care. Many maternity units buy the leaflets, yet little is known about their effectiveness.

We investigated whether the leaflets promoted informed choice and led to increased levels of knowledge, satisfaction with information, satisfaction with the way choices were made, and discussion with health professionals. We also examined whether they changed the actions women took or the services they used.

\section{Methods}

We tested the hypotheses in a cluster randomised controlled trial, with maternity units as clusters, in everyday practice. Qualitative research was undertaken alongside the trial to explore the use of the leaflets in practice and is reported separately. ${ }^{4}$

We randomised maternity units rather than individual women because of the risk of women sharing the leaflets in an individual level trial. Units were included if they had not already purchased the leaflets and had over 1000 deliveries annually. Twelve of the 15 large maternity units in Wales had not already purchased the leaflets and agreed to participate in the study. We also included a small unit under the managerial control of one of the 12 larger units. Maternity units were grouped into 10 clusters because some shared management or clinicians. Clusters were paired on the basis of their annual numbers of deliveries to ensure balance in the two arms of the trial. Members of pairs were randomly assigned by tossing a coin to receive the set of leaflets (five intervention units) or to continue with usual care (five control units). The intervention is described in the box.

\section{Participants}

We identified two samples of women. The first sample was all women who reached 28 weeks' gestation during a six week period and were receiving antenatal care in any setting (antenatal sample). Women were identified through hospital computer systems and the records of

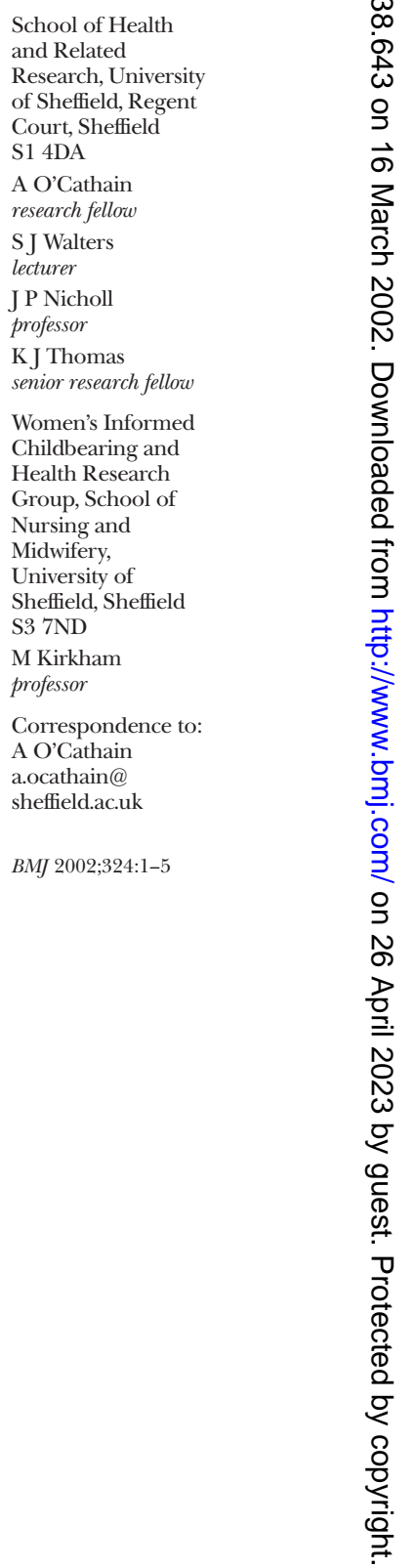




\section{The intervention}

- Ten pairs of Informed Choice leaflets:

- Support in labour

- Listening to your baby's heartbeat during labour

- Ultrasound scans-should you have one?

- Alcohol and pregnancy

- Positions in labour and delivery

- Epidurals for pain relief in labour

- Feeding your baby-breast or bottle?

- Looking for Down's syndrome and spina bifida in pregnancy

- Breech baby: What are your choices?

- Where will you have your baby - hospital or home?

- Leaflets were in pairs-a women's leaflet, designed to be accessible and give information about the benefits and risks of options available, and a more detailed professionals' leaflet, with references for the research on which it is based, which could be accessed by women through the midwife. The leaflets were designed to be given by health professionals to women at different stages of pregnancy

- Each intervention unit received sets of leaflets in May 1998 for an eight month period. A two hour training session was provided for staff. Training material was left with managers for cascade training

- Women in the intervention arm of the trial received the leaflets relevant to early pregnancy at their first booking appointment (10-12 weeks' gestation) and the other leaflets at 34-36 weeks' gestation

midwives and clerks in hospital and community antenatal clinics. The second sample was all women who delivered during a six week period (postnatal sample). Women were identified through child health computer records and hospital and home delivery registers. Women were excluded if they lived outside the catchment area of the hospital or in areas where antenatal care was provided by midwives from other hospitals, were under 16 years old, or had miscarried or if their baby had died or was seriously ill.

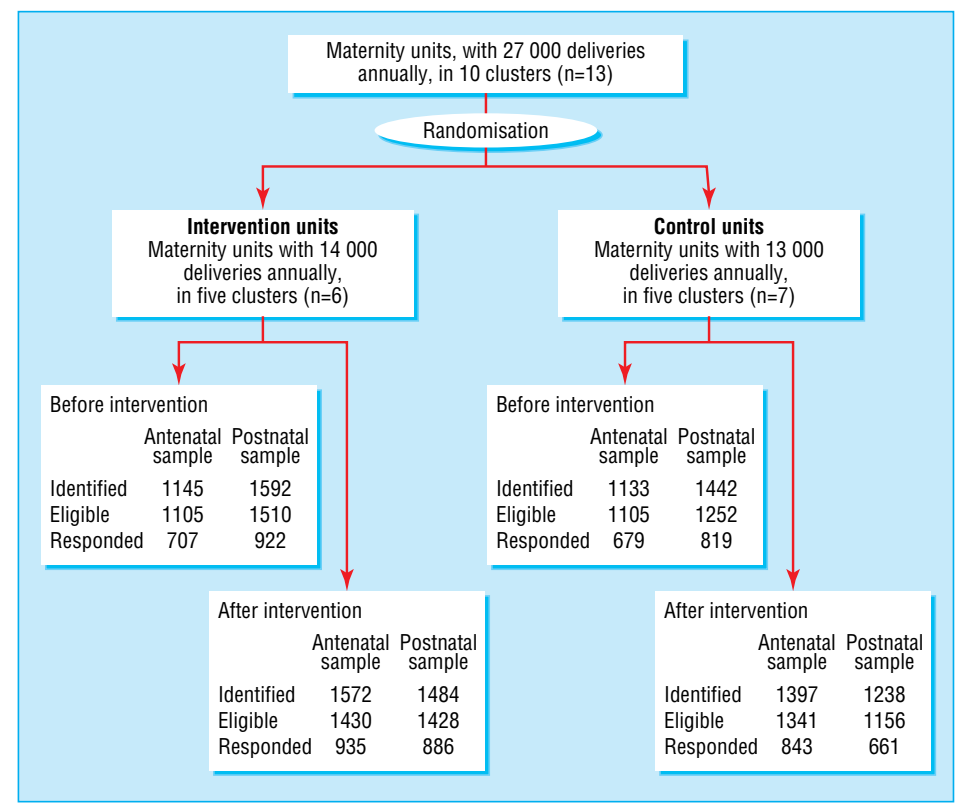

Study design
We identified an antenatal sample and a postnatal sample before the introduction of the leaflets and again nine months after they were introduced. We assessed outcomes using a postal questionnaire sent to women in these four different samples (figure). Women in the antenatal samples received the questionnaire at 28 weeks' gestation, and women in the postnatal samples received the questionnaire eight weeks after delivering their babies. Up to two reminders were sent at intervals of three weeks. The second reminder for the women in the antenatal samples was a shorter questionnaire that covered only key questions.

\section{Outcome measures}

The primary outcome was the proportion of women who answered "yes" to the question "Have you had enough information and discussion with midwives or doctors to make a choice together about all the things that happened during maternity care?" with the options "yes," "partly," "no," "there was no choice," and "did not apply." As informed choice is a difficult concept to measure ${ }^{2}$ we also asked women about the role they took when choices were made, with six options ranging from "active" to "passive."

Secondary outcomes were the "components" and the "consequences" of informed choice. The components measured were women's levels of knowledge of the 10 topics covered by the leaflets; satisfaction with information and with how choices had been made; and views of whether they had had sufficient discussion with health professionals. The consequences measured were the actions taken or services used by women. We also collected data on sociodemographic factors, parity, and women's preferences for involvement in decision making. ${ }^{5}$

\section{Validation and quality assurance}

We developed and piloted some measures specifically for the study on the basis of interviews with women in three maternity units not involved in this trial. ${ }^{6}$ Other measures were modified from published sources. The questionnaires were piloted by post outside the study area. Ethical approval was obtained for the study in each area.

\section{Sample size and statistical analysis}

Assuming an intraclass correlation coefficient of 0.007 and an average cluster size of 200 we calculated we would need a sample size of 925 in the intervention units and 925 in the control units for each of the antenatal and postnatal samples. This would give us an $80 \%$ chance of detecting an increase from $50 \%$ to $60 \%$ in the proportion of women reporting that they made informed choices in the intervention units compared with no change in the control units, at a two tailed significance level of $5 \%$. We paired maternity units to ensure balance and undertook an unmatched analysis. ${ }^{7}$ We compared sociodemographic variables of respondents in all four antenatal samples and in all four postnatal samples at the individual level using analysis of variance and $\chi^{2}$ tests. We compared any changes in the intervention units with changes over the same period in the control units using multilevel modelling. ${ }^{89}$ Analysis was by intention to treat. We adjusted for women's age, age at leaving full time education, parity, and preference for involvement in decision making in the analyses. Intraclass correlation coefficients were 
Table 1 Sociodemographic variables of respondents before and after introduction of intervention. Figures are numbers (percentage) of women unless stated otherwise

\begin{tabular}{|c|c|c|c|c|}
\hline \multirow[b]{2}{*}{ Variable } & \multicolumn{2}{|c|}{ Before } & \multicolumn{2}{|c|}{ After } \\
\hline & Intervention & Control & Intervention & Control \\
\hline \multicolumn{5}{|l|}{ Antenatal $^{\star}$} \\
\hline No of women & 619 & 622 & 827 & 743 \\
\hline Mean (SD) age at leaving full time education (years) & $17.5(2.15)$ & $17.6(2.50)$ & $17.7(2.43)$ & $17.8(2.63)$ \\
\hline Manual occupation $\ddagger$ & $177 / 518(34)$ & $159 / 516(31)$ & $212 / 696(30)$ & $175 / 617(28)$ \\
\hline Preference for active role in decisions & $541 / 608(89)$ & $551 / 611(90)$ & 746/804 (93) & $650 / 722(90)$ \\
\hline \multicolumn{5}{|l|}{ Postnatal } \\
\hline No of women & 922 & 819 & 886 & 661 \\
\hline Mean (SD) age (years) $\dagger$ & $28.0(5.43)$ & $28.6(5.62)$ & $27.9(5.62)$ & $27.8(5.98)$ \\
\hline Mean (SD) age at leaving fulltime education (years) & $17.5(2.56)$ & $17.8(2.58)$ & $17.5(2.38)$ & $17.6(2.34)$ \\
\hline
\end{tabular}

${ }^{*}$ Sociodemographic variables collected on first and second mailings only.

$\dagger P<0.05$ for analysis of variance.

$\ddagger$ Social class information not available for women who had never worked.

Table 3 Women's knowledge of choices in maternity services

\begin{tabular}{|c|c|c|c|c|c|c|c|c|}
\hline \multirow[b]{2}{*}{ Measure } & \multicolumn{3}{|c|}{ Intervention } & \multicolumn{3}{|c|}{ Control } & \multirow{2}{*}{$\begin{array}{l}\text { Mean difference } \\
(95 \% \mathrm{CI})\end{array}$} & \multirow{2}{*}{ 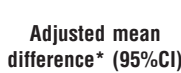 } \\
\hline & Before & After & Change & Before & After & Change & & \\
\hline $\begin{array}{l}\text { Mean (SD) antenatal } \\
\text { knowledge score }\end{array}$ & $3.74(1.43)$ & $3.99(1.57)$ & 0.25 & $3.79(1.52)$ & $3.79(1.52)$ & 0 & $0.25(-0.05$ to 0.55$)$ & $0.20(-0.09$ to 0.49$)$ \\
\hline $\begin{array}{l}\text { Mean (SD) postnatal } \\
\text { knowledge score }\end{array}$ & $3.30(1.65)$ & $3.53(1.64)$ & 0.23 & 3.37 (1.62) & $3.35(1.61)$ & -0.02 & $0.26(0.06$ to 0.47$) \dagger$ & $0.20(-0.05$ to 0.44$)$ \\
\hline
\end{tabular}

${ }^{\star}$ Adjusted for woman's age, age at leaving full time education, parity, and decision style preference.

$+\mathrm{P}<0.05$.

0.01 and 0.002 for the change in informed choice in antenatal and postnatal samples respectively.

\section{Results}

Response rates-The overall response rate to the questionnaires was $64 \%(6452 / 10070)$, with a rate of $65 \%(3164 / 4835)$ for the antenatal sample and $63 \%$ $(3288 / 5235)$ for the postnatal sample. Response rates were lower in women with manual occupations and from ethnic minorities but did not differ by type of delivery, type of pain relief, parity, or age. ${ }^{6}$

Comparison of intervention and control groupsSociodemographic variables of respondents in all four antenatal samples were similar (table 1). Women's age was different in the four postnatal samples, with respondents after the intervention an average of about seven months younger than respondents before.

Impact on informed choice-Before the intervention about half of women in both intervention and control units reported exercising informed choice "overall" in their maternity care. After the intervention, this proportion increased slightly in both groups (table 2) but with no significant difference in the change between groups. Results were similar for the proportion of women reporting active involvement in decision making. In the antenatal samples there were increases in knowledge, discussion, and satisfaction

Table 2 Informed choice and components of informed choice. Figures are numbers (percentage) of women unless stated otherwise

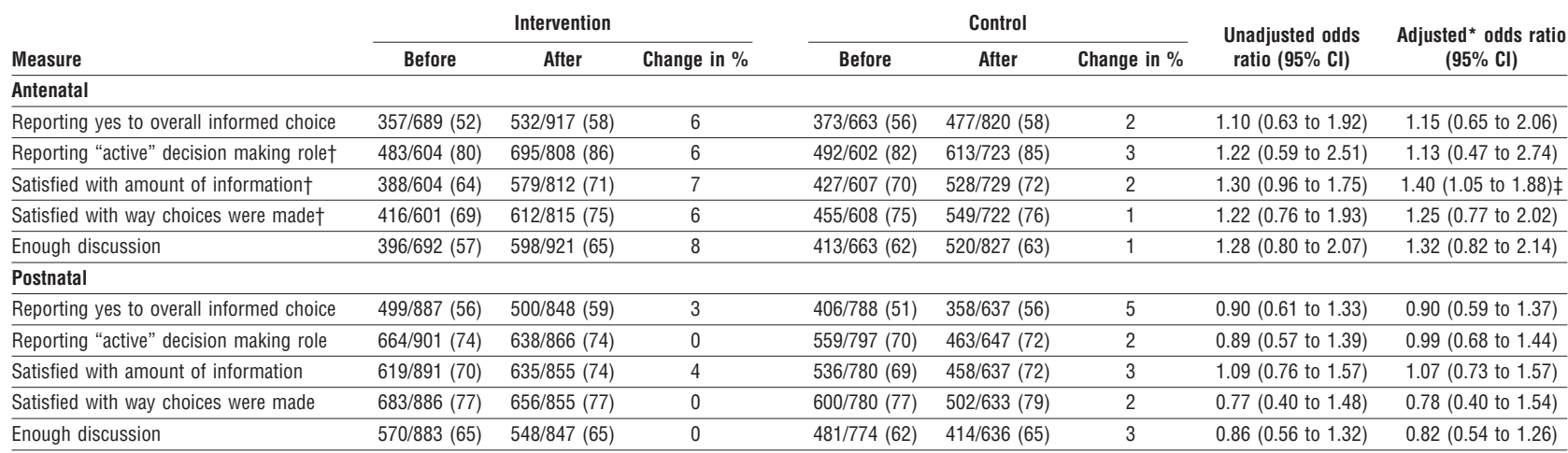

*Adjusted for woman's age, age at leaving full time education, parity, and decision style preference.

†Not included in short questionnaire sent as second reminder to antenatal sample.

$\ddagger \mathrm{P}<0.05$. 
Table 5 Proportion of women who said they had received any Informed Choice leaflet before and after intervention. Figures are numbers (percentage) of women

\begin{tabular}{lcrc} 
& Before & After & Change in $\%$ \\
\hline Antenatal & & & \\
\hline All & $580 / 1241(47)$ & $1048 / 1570(67)$ & 20 \\
\hline Intervention & $266 / 619(43)$ & $598 / 827(72)$ & 29 \\
\hline Control & $314 / 622(50)$ & $450 / 743(61)$ & 10 \\
\hline Postnatal & & & 19 \\
\hline All & $760 / 1741(44)$ & $977 / 1547(63)$ & 31 \\
\hline Intervention & $405 / 922(44)$ & $665 / 886(75)$ & 4 \\
\hline Control & $355 / 819(43)$ & $312 / 661(47)$ &
\end{tabular}

with information and with the way choices were made in intervention units (tables 2 and 3). They were not significant, however, with the exception of satisfaction with information. For this variable the difference in change was less than the minimum important difference of 10 percentage points. There was only one change in postnatal samples, with an increase of 0.24 points on a 10 point knowledge score, which was no longer significant after adjustment for covariates (table 3).

Consequences of informed choice-Given that there was no change in the proportion of women who reported that they exercised informed choice we would not expect changes in choices made. The one significant difference, which was in the proportion of women having screening tests for Down's syndrome and spina bifida, was due in part to an increase in reported uptake in the control units (table 4).

Uptake of leaflets-During the intervention period there was a significant increase in the proportion of women who reported that they had been given any of the Informed Choice leaflets in the intervention units compared with the control units, which showed little change (table 5). However, it was difficult to assess the uptake of the intervention leaflets with any precision. A large minority of women in the intervention units $(44 \%)$ reported that they had been given at least one of the Informed Choice leaflets before the intervention had taken place (table 5). It is possible that a few Informed Choice leaflets were distributed in all the maternity units before the trial. However, most of this reported use probably relates to leaflets other than those under study because women had difficulty in distinguishing the intervention leaflets from other leaflets available in the maternity units.

\section{Discussion}

In this randomised controlled trial the use of Informed Choice leaflets did not change the proportion of women who reported exercising informed choice, or components or consequences of informed choice, in maternity care. This is surprising as a recent systematic review concluded that decision aids improve knowledge and increase the proportion of people who assume a more active role in decision making. ${ }^{3}$

\section{Limitations in design}

Possible limitations of this study are response bias, poor definition of "informed choice," and lack of power. The response rate of $64 \%$ may have introduced some bias, with under-representation of non-white women and women with manual occupations in both intervention and control groups. The pilot study of two of the leaflets suggested that women with manual occupations might benefit more from the leaflets, ${ }^{10}$ suggesting that we may have underestimated the true effect of the leaflets. However, the main study found no relation between social class and effect of the leaflets. ${ }^{6}$

The question used to measure informed choice may have been insensitive. However, we used two different questions and neither showed change. Additionally, we found little change in the components of informed choice, which was consistent with a genuine lack of change in informed choice. Although we recruited fewer women than planned, the analysis for postnatal women was adequately powered due to a smaller intraclass correlation coefficient than estimated for the sample size calculation. The analysis for antenatal women had a power of about $65 \%$. However, observed changes were small, and, although low power can explain the lack of significance, it cannot explain the size of the observed effect. Overall, it is unlikely that the study failed to detect any important change.

\section{Everyday practice}

We carried out this trial in everyday practice. We included thousands of women who might have

Table 4 Consequences of informed choice* in women using maternity services. Figures are numbers (percentage) of women

\begin{tabular}{|c|c|c|c|c|c|c|c|c|}
\hline \multirow[b]{2}{*}{ Measure } & \multicolumn{3}{|c|}{ Intervention } & \multicolumn{3}{|c|}{ Control } & \multirow{2}{*}{$\begin{array}{l}\text { Unadjusted odds ratio } \\
(95 \% \mathrm{CI})\end{array}$} & \multirow{2}{*}{$\begin{array}{l}\text { Adjusted† odds ratio } \\
(95 \% \mathrm{Cl})\end{array}$} \\
\hline & Before & After & Change in \% & Before & After & Change in \% & & \\
\hline \multicolumn{9}{|l|}{ Antenatal } \\
\hline More anxious & $69 / 600(11)$ & $96 / 803(12)$ & 1 & 77/595 (13) & $87 / 724(12)$ & -1 & 1.16 (0.67 to 2.01$)$ & 1.28 (0.72 to 2.27) \\
\hline Drank less alcohol & $474 / 599(79)$ & $623 / 796(78)$ & -1 & $443 / 592(75)$ & $551 / 696(79)$ & 4 & 0.79 (0.59 to 1.06$)$ & 0.72 (0.46 to 1.15$)$ \\
\hline Planned hospital birth & $608 / 619(98)$ & 799/826 (97) & -1 & $604 / 620(97)$ & 725/743 (98) & 1 & 0.50 (0.16 to 1.54$)$ & 0.52 (0.17 to 1.61$)$ \\
\hline Had screening tests & $518 / 619(84)$ & $653 / 824(79)$ & -4 & $437 / 621(70)$ & $589 / 742(79)$ & 9 & $0.48(0.28$ to 0.82$) \ddagger$ & 0.53 (0.33 to 0.92$) \ddagger$ \\
\hline Had ultrasound scan & $619 / 619(100)$ & $826 / 827(100)$ & 0 & $620 / 622(100)$ & $743 / 743(100)$ & 0 & NA§ & NA§ \\
\hline More anxious & 99/879 (11) & $86 / 846(10)$ & -1 & $89 / 772(12)$ & $64 / 630(10)$ & -2 & 0.97 (0.49 to 1.92$)$ & 1.13 (0.57 to 2.24$)$ \\
\hline Stayed in bed during labour & $420 / 888(47)$ & $428 / 847(50)$ & 3 & 409/796 (51) & $319 / 635(50)$ & -1 & 1.19 (0.82 to 1.72$)$ & 1.26 (0.81 to 1.95$)$ \\
\hline $\begin{array}{l}\text { Partner/family present during } \\
\text { labour }\end{array}$ & $867 / 922(94)$ & $836 / 886(94)$ & 0 & $777 / 819$ (95) & $619 / 661(94)$ & -1 & 1.31 (0.79 to 2.18$)$ & 1.39 (0.66 to 2.91) \\
\hline Continuous monitoring & 451/922 (49) & $397 / 886$ (45) & -4 & $387 / 819(47)$ & $319 / 661$ (48) & 1 & 0.81 (0.57 to 1.16$)$ & 0.83 (0.56 to 1.22$)$ \\
\hline Had epidural & $216 / 922(23)$ & $223 / 886(25)$ & 2 & $177 / 819$ (22) & $160 / 661(24)$ & 2 & 1.02 (0.59 to 1.74$)$ & 1.06 (0.57 to 1.98$)$ \\
\hline Breastfed & $518 / 921(56)$ & $511 / 883(58)$ & 2 & 482/818 (59) & $389 / 660(59)$ & 0 & 1.15 (0.75 to 1.77$)$ & 1.11 (0.63 to 1.97$)$ \\
\hline
\end{tabular}

*Not included in short questionnaire sent as second reminder to antenatal sample.

†Adjusted for woman's age, age at leaving full time education, parity, and decision style preference.

$\ddagger \mathrm{P}<0.05$.

$\S$ Not applicable because everything was at $100 \%$ 
received the 10 leaflets, but only $70 \%$ reported receiving one of them. Studies reported in the systematic review of decision aids were explanatory trials, with the implicit assumption that all patients received the intervention. ${ }^{3}$ One conclusion might be that the systematic review showed that decision aids can be effective under certain circumstances but that our study showed that they are not necessarily effective in the real world. The pragmatic nature of our design may have affected the outcome, but that outcome represents a true picture of the impact of introducing the leaflets into clinical practice.

\section{Quality of implementation}

There is some evidence from the trial that there were difficulties with the implementation of the intervention. The accompanying qualitative study shows that the Informed Choice leaflets were not introduced to women as special and different from other leaflets. ${ }^{4}$ Additionally, not all women reported that they had been given any of the leaflets during the intervention. This limited implementation of decision aids is by no means unique to either the Informed Choice leaflets or maternity care. ${ }^{11}$

\section{Generalisability of findings}

The results are generalisable to maternity units that use Informed Choice leaflets to promote informed choice but not to health professionals purchasing the leaflets to guide evidence based practice or individual enthusiastic health professionals purchasing the leaflets to help meet the information needs of their clients.

We thank midwives, managers, and administrative staff in the maternity units in Wales (unnamed to ensure confidentiality of participating units), who worked so hard to help us with data collection. We thank the thousands of women who completed our questionnaires at such an important time in their lives.

Contributors: AO'C contributed to the design of the study, designed the questionnaire, coordinated data collection, contributed to data analysis, wrote the paper, and is guarantor for the paper. SJW contributed to the design of the study, undertook the data analysis, and contributed to the writing of the paper. JPN and KJT contributed to design of the study and the questionnaire, interpretation of the data, and writing of the paper. MK contributed to the design of the study and the questionnaire and writing of the paper. Helen Stapleton contributed to the design and piloting of the questionnaire. Heather Rothwell helped to establish data collection systems. Andrea Shippam and April Dagnell undertook data administration.

\section{What is already known on this topic}

Decision aids can help patients to participate in their care

Ten evidence based leaflets (Informed Choice) are used by maternity services in the United Kingdom to promote informed choice in women using these services

\section{What this paper adds}

The leaflets did not help to promote informed choice in maternity care

Decision aids may not be effective in the real world

Donna Mead, Laurence Moseley, Barbara Bale, Gwenan Thomas, and Sandy Kirkman were members of the research team for the wider study, of which the randomised controlled trial forms a part.

Funding: This work was commissioned by the NHS Centre of Reviews and Dissemination and funded by the Department of Health. The views expressed here are those of the authors and not necessarily those of the Department of Health.

Competing interests: None declared.

1 Charles C, Gafni A, Whelan T. International conference on treatmen decision-making in the clinical encounter [editorial]. Health Expect 2000;3:1-5

2 Entwistle VA. Supporting and resourcing treatment decision-making: some policy considerations. Health Expect 2000;3:77-85.

3 O'Connor AM, Rostom A, Fiset V, Tetroe J, Entwistle V, LlewellynThomas H, et al. Decision aids for patients facing health treatment or screening decisions: systematic review. BMJ 1999;319:731-4.

4 Stapleton H, Kirkham M, Thomas G. Qualitative study of evidence based leaflets in maternity care. BMJ 2002;324:639-43.

5 Degner L, Sloan JA, Venkatesh P. The control preference scale. Can J Nurs Res 1997;29:21-43.

6 Kirkham M, Stapleton H, eds. Informed choice in maternity care: an evaluation of evidence based leaflets. York: University of York, 2001 (report 20).

7 Diehr P, Martin DC, Koepsell T, Cheadle A. Breaking the matches in a paired t-test for community interventions when the number of pairs is small. Stat Med 1995;14:1491-504.

8 Murray DM. Design and analysis of group randomised trials. Oxford: Oxford Murray DM. Design and
University Press, 1998.

9 SAS Institute. SAS/STAT user's guide. Version 6. 4th ed. Vol 2. Cary, NC: SAS Institute, 1989

10 Oliver S, Rajan L, Turner H, Oakley A. A pilot study of two informed choice leaflets on positions in labour and routine ultrasound. York: Social Science Research Unit and NHS Centre for Reviews and Dissemination, 1996 (CRD report 7).

11 Holmes-Rovner M, Valade D, Orlowski C, Draus C, Nabozny-Valerio B, Keiser S. Implementing shared decision-making in routine practice: barriers and opportunities. Health Expect 2000;3:182-91.

(Accepted 5 October 2001) 